earth, and going vertically upwards, Mr. Schlemiiller finds the height of an atmosphere

$$
\begin{array}{lllll}
\text { Of pure oxygen } & \ldots & \ldots & \ldots & 43,360 \mathrm{~m} ., \text { or } 27 \text { miles } \\
\text { Of pure nitrogen } & \ldots & \ldots & \ldots & 49,360 \mathrm{~m} ., \text { or } 31 \text { miles } \\
\text { Of watery vapour } & \ldots & \ldots & \ldots & 76,980 \mathrm{~m} ., \text { or } 48 \text { miles }
\end{array}
$$

These results are, indeed, fair approximations to the ordinary values.

At the end of his treatise the author gives some formula which are destined to serve for the measurement of heights by means of the barometer and thermometer.

On p. 1o there is a curious statement. Supposing the air or gas to be inclosed in a vertical " narrow tube," the author thinks that the molecules will be able to make vertical movements only, and he introduces, therefore, into his calculations the mean value of the vertical components of their velocity, viz., $\frac{V}{2}$. The result is that, according to Mr. Schlemuiller, the temperature in a narrow vertical tube, open at top and bottom, increases four times faster towards the bottom than in the free atmosphere. What the author considers to be a "narrow tube" he shows on p. I2, where he applies his rule to a pit or well (!). It is not too much to say that a perpetuum mobile might be constructed on that principle.

Mr. Schlemiller's formula for measuring heights might be perhaps accepted by some who would take the numerical results given by the author as a sufficient proof of his theory. It is, however, impossible that a theory resting on false assumptions should give correct results, and the coincidence of the results given with data derived from other sources is only apparent. First these data themselves are so varying that it is not very difficult to produce a number approaching pretty closely to some of them; on the other hand, the results calculated from a theory which supposes an atmosphere not exposed to radiation ought not to coincide with data derived from the actual atmosphere, which is far from fulfilling the conditions supposed by the theory.

L. HAJNIŠ

Prague, December 3

\section{Alternative Interpretation of Sensation}

THE curious optical phenomena which form the subject of Mr. Ackroyd's letter (NATURE, vol. xxi. p. 108) have their analogues, as many have probably observed, in other orders of sensation. When travelling by railway, or indeed in any closed vehicle, I have of ten noticed that, if passing objects be shut out from view, it is possible with a little effort to mentally reverse the direction of the train, so that if sensation only were concerned, there would be no doubt as to this reversed motion. Another example of this choice of interpretation is also afforded by the sensations of motion, but in a slightly different way. Standing low down by the water, on a moving steamer or on a bridge over a rapid stream, we can at will either feel that we are moving throngh the water or that we are stationary while the water is flowing by. The same, or at any rate a yery similar, choice is presented when the clouds are scudding over the moon's disk; we can either see the moon travelling behind unmoving clouds, or the clouds passing rapidly across the moon.

It would appear from the above facts that we have in certain cases the power of selecting from the experiences which have been associated with a given set of sensations that one which we wish the sensations to convey. It is difficult to see how this can be explained without admitting a certain amount of freedom of will, as the sum of our previous experience, including the sensation itself, is the same, whether we choose to go backwards or forwards, to stand still or to move on. FRED. D. BROWN

Science Schools, South Kensington, December I6

\section{Curious Incubation}

INDIAN birds avail themselves largely of natural heat in incubating; as breeding-time generally begins in March, the hot weather is generally well on by the time the eggs are laid, and as the temperature of the air is rever below a minimum of $98^{\circ}-100^{\circ}$ during the day, the eggs are but little sat upon except during the night, and so rest and duty are combined judiciously.

On one occasion I collected birds' eggs, and, until I could blow them, I used to place them in a drawer of my office table, and there they would lie for two or three days until I had leisure. One day, while writing, I heard strange sounds from this drawer, and opening it found a young crow (Corvus splendens) emerged from its egg. On a second occasion I similarly found a young myna. I tried hard to rear these strange hatchings, but failed.

One day I saw a kite's nest in the top of a fan palm, and sent up a native to bring down the contents, which turned out to be eggs. In a spirit of mischief I placed them, without saying anything to any one, under a hen which was sitting upon ducks' eggs, and awaited the result. Two days after, my fowl-man came to me with a long and solemn face, and asked permission to address me. That accorded, he mysteriously whispered, "My lord, a great wonder has occurred in the fowl-house; a marvel has happened; devils have been hatched in the fowlhouse." Then began a tableau of descriptive acting which I cannot reproduce. "Did not I place ducks' eggs inder that hen, and, my lord, have not ducks flat feet like this (ftattening and extending his hand), and noses like this (compressing his thumb and index-finger); have they not, my lord?" On my solemnly assenting, he proceeded : "But these devils, my lord, have feet like this (clawing all his fingers), and noses like this (hooking his thumb and index together at his own nose)? Oh! my lord, what shall I do?" "Well, let me see these devils," I replied, sympathisingly; and we walked off to the fowl-house and found the hen sitting dazed beside her basket, in which were five recently-hatched kites. The finale was tragical, for the poor hen abandoned both her eggs and the kites, and the latter would have died had I not had them replaced in their nest. As it was, the ducks' eggs were abandoned.

\section{R. F. HutCHINSON}

\section{THE GEOLOG Y OF THE HENR Y MOUNTAINS}

\section{THE Henry Mountains are a group of five peaks,} ranging in height from 7,000 to $x 1,000$ feet above the sea, which rise out of the table-land, now so well known to all students of physical geography, to which the American geologists have given the name of the Colorado Plateau.

They are situated in Southern Utah, and are crossed by the meridian of $110^{\circ} 45^{\prime}$ and the thirty-eighth parallel.

They stand close upon the northern bank of the Colorado, which flows past their base in a canon 1,500 feet in depth.

Mr. Gilbert's account of the geology of these mountains is specially interesting to the student of physical geology, on account of the explanation it contans of the machinery by which their uplift was brought about. His views have certainly the merit of novelty, and at the same time the evidence in their favour, if not quite conclusive, carries with it considerable weight.

All previous speculation on the subject of mountain. building may be grouped under two heads. Nearly all mountain ranges have a central axis or core of crystalline rock. By the older geologists this crystalline mass was looked upon as intrusive, and it was believed that the violent injection of a huge body of molten matter had lifted up the stratified rocks through which it forced its way, and shouldered them off on either side, giving them a dip coinciding in direction and approximately in amount with the slopes of the chain. A section across a mountain chain would show, according to this view, an anticlinal arrangement of the bedded rocks with a body of intrusive rock in the centre, and it was the intrusion of this central mass that was believed to have caused the upheaval. The force, then, which according to this view, raised mountains to their present elevation, was of the nature of a thrust acting vertically upzuards.

Never, perhaps, did any theory collapse more completely than this when it came to be subjected to the test of examination in the field. As mountain chains were one by one investigated by geologists, the anticlinal arrangement of their rocks which this theory required was found to be more and more conspicuous by its absence. Marked peculiarities of structure were indeed found to be so universally present in mountain chains, that no range of hills was deemed worthy of that title I "Report on the Geology of the Henry Mountains." By G. K. Gilbert. (Washingtcn, $x 877$.) 
unless it possessed them. But these characteristic structures were vastly different from the simple anticlinal tilting which the earlier speculators had believed to be the typical arrangement of the beds in a mountain chain. It was found that the rocks had been folded into a number of very sharp troughs and arches whose axes ran roughly parallel to the trend of the chain. The radii of some of the curves were measured by miles, while in other cases the beds had been puckered up into minute and complicated convolutions. Frequently the arches had been canted over, and inversion of the beds had been produced. Slaty cleavage had been largely developed, the planes of cleavage having the same general bearing as the axes of the range. Faulting had taken place on a large scale, and the rocks were often jammed and mashed together till a state of confusion that defied description had been produced.

No single thrust acting vertically upwards could have brought about such results as the repeated folding, the inversion, the cleavage, and the smashing; but everything pointed to powerful. pressure acting in a horizontal direction which had wrinkled up a vast thickness of strata into mighty folds, and sometimes jammed them together till they became little better than a mash of shattered and ruined rock. The crystalline core was in some cases nothing more than the result of intense metamorphism; and where it was intrusive, there was every reason to think that the molten or pasty rock had been driven up through fissures by the squeezing which the rocks had undergone; in fact, so far from the crystalline centre being the cause of the upheaval, its presence was only one of the results which almost necessarily followed from the way in which that upheaval had been brought about.

All the facts then seemed to show that mountain chains had not been uplifted by a force acting vertically upwards, but had been ridged up by a squeezing force acting horizontally on a very thick mass of strata.

That denudation carved into shape the mass as it rose was soon realised, but we are here concerned only with the early stages in the genesis of a mountain chain.

Now one point of great interest in the geology of the Henry Mountains, is that they seem at first sight to form a striking exception to the law of arrangement, perhaps we might more properly say disarrangement, which prevails so widely in mountain chains. They might also, to a casual observer, seem to supply a case where the structure assigned by the earlier geologists to mountain ranges, and which has been looked for in vain so often, does really exist.

Careful investigation, however, shows that neither of these suppositions would be true.

The structure of the Henry Mountains is simple when compared with the complicated foldings and disturbances so characteristic of mountain chains. In the case of each of these mountains the strata are arranged in domeshaped fashion dipping outwards in all directions from the centre. The strata of the plateau from which they rise are all but horizontal; around the base of each mountain the beds bend up and "rise, slowly at first, but with steadily increasing dip, till an angle of $45^{\circ}$ is reached. The dip then steadily diminishes to the centre, where it is nothing." In some cases the beds slope away from a single centre, in others a great arch is made up by the confluence of a number of smaller domes.

Widely different as this arrangement is from the complicated contortion and disturbance usually met with in mountain chains, the Henry Mountains furnish no exception to the broad generalisation that mountain chains always exhibit intense convolution and smashing of their rocks. For the Henry Mountains are in no sense a mountain range. They are a group of peaks, each of which is an isolated individual; they show little or no tendency towards a linear arrangement; "they would prove perfectly intractable in the hands of those geologists who draw parallel lines through groups of volcanic vents by way of showing their trend. They are as perfectly heterotactous as they could be made by artificial arrangement."

In the case of several of the Henry Mountains the centre of the hill is seen to be occupied by a core of intrusive trachyte, from which intrusive sheets and dykes are given off. Reasoning from analogy Mr. Gilbert believes that in those cases where no such core can be seen, there still is one present under ground, but as yet uncovered by denudation. The upper surface of these cores is arched, and seems to run parallel to the bedding of the overlying rocks. It certainly looks as if we had here a case when strata originally horizontal had been bent up into a dome by the injection from below of a mass of molten rock. And this is the explanation adopted by Mr. Gilbert, but his views differ widely from those which the earlier geologists would have maintained had they been acquainted with these mountains. The earlier speculators gave to their intrusive masses a wedge-shaped form, representing them as broadening downwards and extending to the lowest depths to which geological speculation ventured to penetrate. The intrusive cores of the Henry Mountains, on the other hand, are represented by Mr. Gilbert as bounded on their under side by a horizontal plane and as resting on horizontal strata. They have, in fact according to him the shape of a huge plano-convex lens, with its flat face downwards; the curved surface is however rather a portion of an oblate spheroid than a sphere, for the trachytic masses are somewhat flattened on the top; some of them too are oval rather than circular in plan. To an intrusive mass of this shape he gives the name of a laccolite, from $\lambda a ́ k$ kos, a cistern, and $\lambda i \theta o s$, stone.

His theory of the genesis of a laccolitic mountain is as follows :-Lava was pumped up through a chimney or fissure and at a certain point in its upward course spread itself out between two adjoining beds in the form of an intrusive sheet; by farther additions of lava from below the sheet is thickened, the overlying strata are more and more arched, till at last they are bent up into a dome.

Of course this involves the stretching of the overlying strata; in the case of one of the domes it is calculated that there must have been an extension of 300 feet in three miles. Mr. Gilbert has shown that this elongation. is rendered possible by the fact that at the time of their flexure the beds were loaded by a crushing weight; directly the tension exceeded the limits of cohesion, and a fissure was torn open, or rather directly a fissure would have been torn open had the bending taken place at the surface, the weight of the pile of strata overhead crushed together the walls and closed the rent. That a cover of rock, perhaps 7,000 feet, and possibly I I,000 feet in thickness, would tend to this result is clear enough, but that it did not always prevent rupture is shown by the numerous dykes associated with the laccolites. Mr. Gilbert has attempted to show by mathematical calculation that at a given depth the overlying strata could not be lifted if the area of the laccolite falls short of a certain value. His method involves certain assumptions which render it somewhat unsatisfactory, and his conclusion seems to be inconsistent with the explanation he gives of the formation of a laccolitic mountain; for according to him the first step in that process is the production of an intrusive sheet. This in itself involves the uplifting of the beds above, and his calculations show that no uplifting could take place till the sheet had reached a certain size.

The failure, however, to solve by mathematical methods a problem of this difficult nature by no means implies a rejection of the theory. A much more important matter is the examination of the evidence by which the existence of these peculiarly shaped bodies of intrusive rock is supported. Mr. Gilbert has evidently seen enough to satisfy himself on this point, and we 
are quite willing to put every confidence in the statements of so accurate and skilful an observer; at the same time we cannot help feeling some regret that he has not been a little more explicit in his description of the sections which lay open the characteristic form of the laccolite. The horizontal base and the undisturbed state of the underlying strata are the first points on which we wish to be thoroughly assured. It is stated that "in five instances one side of the dome of strata has been washed away, exposing the core of trachyte to its base, and showing undisturbed strata beneath." We do not doubt the statement, but we should have been better satisfied if these cases had been described more in detail in the special account of the separate mountains. The views of the Marvine laccolite in Figs. 43 and 44, if we understand them aright, do seem to be conclusive on the point of the horizontal base; but the evidence would have been more convincing if these plates had been explained at greater length in the text. In fact, the one fault we have to find with the book is the difficulty of understanding the illustrations; they are not striking from an artistic point of view ; in some the letters of reference are so indistinct that they can be found only with the utmost difficulty, and we confess that by some we have been fairly beaten; we should, for instance, very much like to know which is the laccolite in Fig. 33 .

Again, the evidence for the parallelism between the upper surface of the laccolite and the bedding of the overlying rocks, has hardly been brought out with sufficient distinctness ; after a comparison, for instance, of Figs. 25 and 26 , an invidious critic might have something severe to say about the proportion which the part of the laccolite actually seen bears to that which is admittedly theoretical.

But we have made these remarks in no captious spirit; we wish merely to express our fear that the acceptance of Mr. Gilbert's ingenious speculations may be hindered by a lack of detail in the statement of the evidence he brings forward in support of them.

Assuming Mr. Gilbert's theory to be sound and good, it is not likely that the Henry Mountains are the only ones constructed on the laccolitic type. Mr. Gilbert is inclined to class under this head a number of mountains in the western territories, grouped together under one type by Dr. A. C. Beale, in a paper in No. 3 vol. iii. of the Bulletin of the United States Geological Survey. We cannot say that there is anything in Dr. Beale's description which would lead us to assign these mountains to the laccolitic group; and in one case, that of the Elk Mountains, the careful account given in the Report for 1874 of the Geological and Geographical Survey of the Territories, seems to show that they form a normal mountain range ridged up by horizontal pressure.

There is one problem which has been always more or less of a puzzle to the student of volcanic phenomena, on which Mr. Gilbert's speculations may possibly throw considerable light: we mean the formation of pit-craters. Mr. Scrope showed how these singular depressions had probably been blown out by one single explosion of unusual violence, and Mr. Judd has suggested their connection with intrusive sheets. If we suppose a rapid accumulation of lava in a laccolitic mass, and a sudden development within it of steam of high tension, we shall have exactly the conditions suitable for producing one of those explosions which there is every reason to think have been the cause of pit-craters.

The work contains a long and elaborate chapter on "Earth Sculpture," which space will not allow us to do more than mention, and concludes with a chapter on Economics, in which the author insists with almost pathetic earnestness, that the Henry Mountains, full of interest as they are for the geologist, can never be put to any profitable account commercially, unless possibly in parts for grazing. Nature would seem here to have laid herself out to frame a district which should have attractions for no one but the student of pure science.

A. H. G.

\section{FINNIC ETHNOLOGY}

$A$ DECIDED stage in the progress of Finnish studies $\mathrm{A}$ is marked by the sumptuous work on "Finnish Crania," recently published by the native ethnologist, Gustavus Retzius. ${ }^{1}$ Continuing the investigations of his father, Anders Retzius, this distinguished anthropologist has at last been enabled to arrive at some definite conclusions both as regards the type itself and its geographical area. The elder writer was a warm advocate of what may be called the Finno-European theory, which is still popular amongst a certain school of fearless anthropologists, and which, since the discovery of the Cuneiform writings, has received a fresh impulse and a wider extension. This is not the place to discuss the angry question of the FinnoUgrian relations to the Accad language and civilisation of Babylonia. But many enthusiasts will probably be disappointed to hear that the younger writer abandons his father's position, and deals a severe blow to the doctrine of a former wide-spread diffusion of the Finnish race over the greater part of Central and Western Europe. The laborious attempts of many ingenious philologists to discover traces of Ugrian affinities in the Italic and Teutonic tongues, and even to remove the Etruscan from the Aryan to the Ural-Altaic family, can scarcely be regarded as at all successful. On the other hand, a few ancient skulls presenting certain traits characteristic of the same race, together with some hatchets and other stone implements picked up here and there analogous in form to those often dug up in Finland, offered far too flimsy materials to supply a solid basis for such a vast superstructure. Hence it is not perhaps surprising that in the light of further investigation and more serious research the theory should prove to be somewhat visionary.

History had already pointed out that during the ascendency of the Goths from the Baltic to the Euxine the Finns were found nowhere to the west, but only to the east and north of that line ; in fact in their present homes on the Volga, in Finland, round about the great Russian lakes, and more recently along the southern shores of the Gulf of Finland. It might doubtless be argued that at this period the race had farther west been already absorbed by the Slavs and Teutons of Aryan stock, intruders from Asia. But no reliable data can be appealed to in support of this position. The authenticity of the stone hammers and other objects of Oriental form said to have been found in France and elsewhere is now questioned, while the philological argument never gets beyond the purely etymological stage.

Hence Gustavus Retzius adopts the view now fast gaining ground, that instead of being the aborigines of Western and Central Europe, the Finns are amongst the most recent arrivals from Asia. Their own traditions point to the Altai region as their true home; the national usages and the spirit of the popular songs embodied in the great epic, the Kalevala, are all Asiatic rather than European, and the uninterrupted stream of their migrations westwards may still be clearly followed from their most advanced outposts in the Scandinavian peninsula through Finland, along the Volga and Kama valleys, over the Urals, and up the Obi basin to the probable cradle of their race in the Sayan highlands.

The narrower, though scarcely less interesting question of the position of the Finnic branch in the Ural-Altaic family is still surrounded with difficulties, which seem to be intensified rather than removed by the conclusions of M. Retzius. While the Finnish language is no doubt fundamentally connected with those of the other members of the group, the physical features of the race present “ "Finska Kranier." Skildrade af Gustaf Retzius, Stockholm, 1878. 